\title{
The effects of variation in seed size on growth and reproduction in the wild barley Hordeum vulgare ssp. spontaneum
}

\author{
B. E. Giles*
}

Department of Crop Genetics and Breeding, The Swedish University of Agricultural Sciences, S-268 00 Svalöv, Sweden.

The size of a seed is known to affect the fitness of the plant growing from it; larger seeds often have the higher fitnesses. Based on the assumption that most seed size variation will be found among genotypes, reductions in the variance of seed size, due to selection towards seeds of similar and larger sizes have been predicted, but unfortunately, not observed. Many plant species produce seeds which vary in size due to their position in the inflorescence or fruit. I thus wanted to see if the variation in seed size within a plant created variation in fitness and if so, whether this might explain why the expected reduction in variance is not observed. Pairs of seeds from the selffertilizing Hordeum vulgare ssp. spontaneum, sharing maternal and paternal genotype, maternal environment and growth environment but differing in the amount of endosperm available to the embryo, were used. Initial seed size affected time of germination, seedling growth rate and the number of seeds produced. There were, however, no differences in the means of the sizes of seed produced by genetically identical individuals, which can be explained if the position effects are regenerated by seeds of different sizes. It is proposed that it is not a particular seed size which characterises a genotype but a particular distribution of sizes. Position effects are the agents creating the size distributions which ensure that seed size and fitness variation is produced every generation. Evidence is presented which suggests that variation in the expression of position effects exists and may be available to selection. The evolutionary role of this variation is considered in light of current models.

\section{INTRODUCTION}

In plant species which produce seeds containing endosperm, the size of a seed is primarily determined by the amount of endosperm it possesses; the endosperm is the maternal resource available to the embryo for germination and seedling establishment.

Variation in seed size has been observed in many species among populations, among plants within populations and within single plants (e.g., Antonovics and Schmitt, 1986; Janzen, 1977; Pitelka et al., 1983; Schaal, 1980; Stanton, 1984a, b; Thompson, 1981; Waller, 1982; Wolf et al., 1986; Wulff, 1986b,c). While seeds of particular sizes appear to be favoured in particular environments (e.g., see Baker, 1972; Janzen, 1977, Morse and Schmitt, 1985; Stanton, 1984b; Wulff, $1986 b$ ), seed size has also been observed to affect the time and probability of germination, seedling

\footnotetext{
* Present address: Department of Genetics, University of Umeå, S-901 87 Umeå, Sweden.
}

survival and/or adult reproductive output within the same environment (e.g., Black, 1957; Cidiciyan and Malloch, 1982; Morse and Schmitt, 1985; Schaal, 1980, 1984; Stanton, 1984a, b, 1985; Wulff, $1986 b, c)$. Most of the published studies dealing with seed size have shown that the environment in which the seed lands is remarkably effective at selecting which size of seed grows and reproduces.

Another common observation (e.g., above references) is that characters related to fitness are positively correlated with seed size, such that larger seeds have the higher fitnesses (but see Ambrose and Hedley, 1984, p. 68). These observations have been used as assumptions in several theoretical models (e.g., Smith and Fretwell, 1974; McGinley et al., 1987) which predict that a reduction in the variance of seed size, due to strong selection towards seeds of a similar and larger size, should be observed. This should occur as the frequencies of genotypes producing seeds of favoured sizes increase at the expense of genotypes producing seeds of other sizes, if the variation in seed size, and consequently the variation in fitness, is geneti- 
cally determined. Unforunately, these expectations are not borne out (e.g., references above); high levels of variation in seed size are continually produced in natural populations. One of the central questions in studies of the evolution of seed size is thus, why, despite the striking differences in the fitnesses of plants growing from seeds of different sizes, is the prediced reduction in seed size variance not observed?

One obvious explanation is that the variation in the sizes of seeds produced by a plant genotype is predominantly environmental. The control of seed size in natural populations has been investigated in a few studies. The approach has been to measure the proportion of the variation due to genetic differences among individuals, to identify the source(s) of the genetic variation and then to ask whether, or at what level, this character is subject to natural selection. Antonovics and Schmitt (1986), Mazer et al. (1986), Mazer (1987) and Schaal $(1980,1984)$ have shown, with respect to the variance in seed size that: (1) by far the largest component is environmental (2) most of the environmental component is due to withinplant variance and (3) the largest component of the genetic variance is due to differences among maternal lines. The size of the environmental variance has been interpreted as suggesting that little response to selection can be expected, while the predominantly maternal determination of the existing genetic variance indicates that any selection response which might occur will be slow (e.g., Naylor, 1964).

The largest component of this environmental variance, namely, the within-plant variation, has ral sources; e.g., time of fruit production (e.g., ers and Steel, 1984), numbers of seeds per plant ruit (e.g., Bradford and Smith, 1977; Giles and gtsson, 1988; Giles and Lefkovitch, 1985; Nickell and Grafius, 1969; Olsson, 1960; Stanton, $1984 b$; Werner and Platt, 1976), fruit position (e.g., Harper et al., 1970, p. 72), and seed position within a fruit or inflorescence (Mazer et al., 1986; McGinley, in press; Schaal, 1980; Stanton, $1984 a, b)$. In particularly, individual plants of many species in the Asteraceae, Chenopodiaceae, Poaceae, Leguminaceae and Brassicaceae (Harper, 1977), always produce seeds whose sizes vary continuously as a result of their position on the maternal plant (i.e., within fruit or inflorescence). The studies of Antonovics and Schmitt (1986), Mazer et al. (1986), Mazer (1987) and Schaal (1980, 1984) described above, all used species which came from this group of five families; it is thus interesting that the primary source of the environmental component of seed size variance was the variation within plants.

The inference that within-plant variance is environmental can also be an artefact of statistical analyses which partition total phenotypic variance into components; e.g., analyses of variance and diallels as used by Antonovics and Schmitt (1986), Mazer et al. (1986). Mazer (1987). If the aim of an experiment is to determine how much of the total variance in mean seed weight is available for selection, i.e., is genetic, then one naturally choses to compare different genotypes and/or the offspring of their crosses. The variance in seed size contributed by the within-plant component then becomes the residual or error term against which all other effects are tested. By convention, the within-plant variance cannot be interpreted as anything other than environmental variance from these analyses. This convention also implies that this particular environmental variation is a random effect. If, however, the distributions of seeds of different sizes are examined in individual plants from species belonging to the five families listed above, the size variation is not found to occur randomly throughout the plant, but in a structurally ordered manner within a fruit or inflorescence. It may thus be biologically misleading to regard the within-plant variance, estimated from plant species with position effect variation in seed size, as random environmental variance. It also becomes less likely that random environmental variance, as the primary determinant of seed size variation, solely explains why we do not observe the expected reduction in the variance of sizes of seeds produced, in spite of the strong selection for size in the growth environment.

It has also been suggested that the expected reduction in variance is not observed because the primary source of seed size variation arises from constraints due, for example, to the spatial packing arrangement of flowers/seeds, or developmental gradients such as differences in flowering time which lead to differences in seed-filling duration within the inflorescence (e.g., Mazer et al., 1986; Roach and Wulff, 1987; Silvertown, 1984; McGinley et al., 1987; McGinley, in press; and personal observations in both wild and cultivated barleys). Here it is assumed that what we observe as maternal position effects are the by-product of these constraints, and the resulting variation is neither purely environmental in the sense of being random, nor genetic variation which is available to selection. That these maternal position effects appear to be species-specific and occur in a structurally ordered manner within a fruit or inflores- 
cence suggests that within-plant variation arising from position effects is inherited. The key question is whether position effects, regardless of their causes, contain genetic variation available to selection. To answer this, we must test whether position effects follow different patterns among individuals within species and whether these differences are inherited before using the "developmental constraints" argument as an apology for our failure to observe an expected reduction in seed size variance.

Why be concerned about the variation in seed size within, or even among, plants? The simple fact that a seed must germinate before a plant exists, let alone reproduces, suggests that seed size could be a primary determinant of the genetic structure of plant populations and that selection acting on seed size could thus affect the frequencies of all genes (i.e., as if the whole genome were hitch-hiking on seed size). If size is as important a determinant of fitness as it appears to be, and if size variation is predominantly random, then gene frequencies could also vary at random in a population, depending on which seed size happened to be favoured at any particular instant. This thought, and the observation that seed size variation appears to be maintained in natural populations, suggested that the effects and causes of the size variation within a plant, in addition to those between, should be investigated.

This paper is the first in a series investigating the nature and role of within-plant variation in seed size for the population dynamics of plants characterised by the production of seeds which vary in size due to position effects. The highly self-fertilizing plant, Hordeum vulgare ssp. spontaneum (Poaceae), will be used as the main experimental organism. The purpose of this paper is two fold. The first is to determine whether and how size differences of the sort generated by position effects affect the fitnesses of the resulting plants; i.e., does seed size, in the absence of genetic and environmental differences, affect germination, seedling and/or adult fitness? To do this, I compared pairs of seeds which differed in size but which shared maternal and paternal genotype, maternal environment (see Alexander and Wulff, 1985) and experimental environment. Second, the results of these experiments and others from the literature will be used to support the hypothesis that within-plant variation arising from position effects is inherited and contains variation available to selection. These results provide another explanation for why, despite the striking differences in the fitnesses of plants growing from seeds of different sizes, the predicted reduction in seed size variance is not observed.

\section{MATERIALS AND METHODS}

\section{Materials}

Seeds of the wild barley, H. v. ssp. spontaneum and cultivated barley, H.v. ssp. vulgare were studied. Ssp. spontaneum is a colonizing, selffertilizing anual of the Mediterranean, North Africa, Asia and China and is the sole progenitor of cultivated barley, ssp. vulgare. Differences in seed size have been observed both among and within ssp. spontaneum populations (Giles and Lefkovitch, 1985; Giles and Bengtsson, 1988). In both subspecies, variation in seed size is also found within a single plant; the seeds in the middle of the head are larger than those at either end. Both ssp. spontaneum and vulgare appear to be adapted to self-fertilization as neither inbreeding depression nor heterozygote superiority are known to occur; e.g., little heterotic gain has been obtained in breeding programmes for hybrid barley cultivars.

\section{Background}

This experiment was part of a larger study of the variation in life history characters in 888 individuals from 17 field-collected populations (accessions) of ssp. spontaneum. The seed material was kindly given to me on the understanding that I increased the size of the seed samples from these accessions for further experiments. From ten of the 17 populations, I received only one seed from each plant (188 plants). From each of the seven populations used in this paper (table 1 ), I received two seeds from a single spike from each of 50 plants. Half of the endosperm (distal end) from one of each pair of seeds had, however, been removed for hordein analysis, leaving me with 350 whole seed/half seed pairs from these seven populations. Since it was essential to maximise the amount of seed produced from these accessions, "half-seeds" were also planted. Since I wanted to analyse the variation in the life history characters, I planted whole and half seeds in a randomized block design (see below) so that I could partition out the effects of whole and half seeds on the life history characters as an orthogonal comparison while simultaneously increasing the size of the seed sample. 
Table 1 A description of collection sites of populations used in the whole seed/half seed comparison. Population numbers correspond to Scandinavian Hordeum accession numbers

\begin{tabular}{|c|c|c|c|c|}
\hline Region & $\begin{array}{l}\text { Accession } \\
\text { number }\end{array}$ & Location & Latitude/longitude & Habitat \\
\hline Turkey & $\begin{array}{l}3013 \\
3014\end{array}$ & $\begin{array}{r}7 \mathrm{~km} \mathrm{E} \text { of Siverek } \\
20 \mathrm{~km} \mathrm{E} \mathrm{of} \mathrm{Siverek}\end{array}$ & $\begin{array}{l}37^{\circ} 50^{\prime} \mathrm{N} / 39^{\circ} 50^{\prime} \mathrm{E} \\
37^{\circ} 50^{\prime} \mathrm{N} / 39^{\circ} 20^{\prime} \mathrm{E}\end{array}$ & $\begin{array}{l}\text { Primary, basalt hillside } \\
\text { Secondary, weed in cereal field }\end{array}$ \\
\hline Iran & $\begin{array}{l}3015 \\
3016 \\
3017 \\
3018 \\
3020\end{array}$ & $\begin{array}{l}18 \mathrm{~km} \mathrm{~W} \text { of Gawdar } \\
29 \mathrm{~km} \mathrm{~W} \text { of Gawdar } \\
35 \mathrm{~km} \mathrm{SW} \text { of Ilam } \\
\text { Ilam-Meheran Transect } \\
3 \mathrm{~km} \mathrm{E} \mathrm{of} \mathrm{Qazvin}\end{array}$ & $\begin{array}{l}33^{\circ} 50^{\prime} \mathrm{N} / 46^{\circ} 35^{\prime} \mathrm{E} \\
33^{\circ} 35^{\prime} \mathrm{N} / 46^{\circ} 35^{\prime} \mathrm{E} \\
33^{\circ} 17^{\prime} \mathrm{N} / 46^{\circ} 24^{\prime} \mathrm{E} \\
33^{\circ} 33^{\prime} \mathrm{N} / 46^{\circ} 28^{\prime} \mathrm{E} \\
36^{\circ} 20^{\prime} \mathrm{N} / 50^{\circ} 00^{\prime} \mathrm{E}\end{array}$ & $\begin{array}{l}\text { Primary, south facing rock slope } \\
\text { Secondary, edges of wheat field } \\
\text { Primary, rocky area } \\
\text { Secondary, edges of cultivated fields } \\
\text { Secondary, weed in irrigated fields }\end{array}$ \\
\hline
\end{tabular}

Soon after the start of the experiment, it become obvious that while the "half seeds" germinated faster, they soon grew less vigorously than plants from "whole seeds". Since each whole seed/half seed pair came from a single spike of a highly self-fertilizing species, each pair of seeds shared (i) maternal and paternal genotype, and as near as possible, (ii) maternal and experimental environments. Thus, it was the experimental removal of endosperm from one of the seeds in each pair which allowed/suggested the question, "Does the amount of maternal resource available to an embryo affect germination, seedling and/or adult fitness in the absence of genetic and environmental differences?" As there were potentially 350 different genotypes and maternal environments represented by these pairs, differences within each pair made up the unit of comparison for this experiment. For convenience, plants grown from whole and half seeds will be referred to as WS and HS plants, respectively.

The large differences observed between WS and HS suggested that naturally occurring variation in seed size might have similar effects on life history characters. Two further experiments were designed in order to confirm the observations on WS and HS plants (Experiment II) and to establish whether unmanipulated large and small seeds behaved similarly to whole and half seeds (Experiment III).

\section{Experiment I}

All seeds were after-ripened to remove effects of differential dormancy and then germinated individually in small pots filled with Hammenhögs standard potting mixture. So that germination time could be measured, the seeds were placed on the soil surface, watered and covered with dark plastic. Each seed was covered with soil after radical and coleoptile emergence and the plastic removed after six days. Two weeks after the seeds had first been watered, they were vernalised for six weeks at $2-4^{\circ} \mathrm{C}$ and 7 hour days.

After vernalization, each seedling was planted in a one litre pot which was then placed on the dirt floor of a greenhouse. Day and night temperature ranges were $20-24^{\circ} \mathrm{C}$ and $14-18^{\circ} \mathrm{C}$, respectively. Day length was maintained at 18 hours throughout the experiment.

The particular greenhouse available for use contained several rows of lamps, each row $2 \mathrm{~m}$ apart, across the width of the greenhouse. The only way in which the material could be grown so that all plants were exposed to similar environmental conditions was to place the plants in rows under each bank of lamps. As day and night temperatures were found to be similar under the six rows of lamps in the middle of this greenhouse, these six rows of lamps were chosen. Rows of plants 3-pots wide and 46-pots long accommodated all plants under these lamps. The lamps were adjusted so that light intensities within and among the six rows were even. WS and HS plants from each population were equally and randomly divided among the six rows with each WS and HS pair somewhere in the same row.

The following characters were measured on each WS and HS plant: (1) time of radical emergence--RADT (hours) (2) time of coleoptile emergence-COLT (hours) (3) time of first leaf maturation-FLMT (days) (4) first leaf length after 12 days--FLFL ( $\mathrm{mm})(5)$ tiller number one week after completion of vernalization-TNO (count) (6) flowering time--FLWT (days) (7) Culm lengthCLML (mm) (8) Flag leaf length-FLL (mm) (9) flag leaf width-FLW (mm) (10) awn lengthAWNL (mm) (11) head length-HDLG (mm) (12) 10-seed weight-SDWT (g) (13) spike numberSPNO (count). Characters 6-12 were measured on the first flowering spike produced by the plant. All characters were log-transformed. The difference between plants derived from whole and half seeds 
from the same plant was tested for significant deviation from zero using a paired $t$-test. If one member of a pair died during the experiment or was missed during measurement, the pair was excluded from analysis.

\section{Experiment /I}

Fourteen seeds from each of five ssp spontaneum plants from each of two populations (3013 and 3016 , table 1) and 70 seeds from a bulk sample of each of the ssp. vulgare cultivars, Tellus and Etu, were chosen from a weighed sample of seeds such that the maximum variation in seed weight within each population or cultivar was limited to $5 \mathrm{mg}$. Half of the seeds from each plant or cultivar were cut in half. The seeds were germinated on moist filter paper.

The precise times of germination were not recorded for each seed although rough patterns of coleoptile emergence were noted. Because there was an interest in studying the effects of seed size on both root and shoot, a liquid culture was used. The germinated seeds were placed in plastic holders which hooked onto the sides of 2 litre blackened beakers. The beakers were filled with 1.8 litres of a complete nutrient solution and a piece of dark plastic was cut and placed in open spaces between the holders to provide darkness for the roots and to prevent algal growth. Eight plants, consisting of four whole seed/half seed pairs from each cultivar or population were grown in each beaker. Thirty-five such beakers were used in this experiment. In order to keep all factors other than seed size as similar as possible, the beakers were placed in a growth chamber and their positions changed randomly each day. The nutrient solutions were replaced every second day so that nutrients were not limiting and competition effects were reduced.

All plants were harvested at the end of two weeks and the following characters measured: (1) length of the first leaf after 12 days-FLFL ( $\mathrm{mm}$ ) (2) shoot length (measured from the base of shoot to the tip of the longest leaf)-SLENG (mm) (3) shoot fresh weight-SFRESH (g) (4) shoot dry weight-SDRY (g) (5) root length (measured from the top of the root to the tip of the longest rootRLENG (mm) (6) root fresh weight-RFRESH (g) (7) root dry weight-RDRY (g) (8) tiller number-TNO (count) (9) crown root numberCRNO (count). Two-way analyses of variance, using populations and size classes (HALF vs. WHOLE) as main effects, were used to analyse the results. Because of missing data, SAS-GLM program was used. Log transformations of the length and cube root transformations of the weight characters were used to normalise the variances.

\section{Experiment III}

Sixty seeds from each of the cultivars, Tellus and Etu, were weighed, labelled and germinated on moist filter paper. After germination, the seeds were carried through the beaker experiment described above. This time, 15 seeds from a single cultivar were placed, randomly with respect to seed size, in each beaker. Thirty plants were harvested from each cultivar at the end of two weeks and the remainder at the end of four weeks. The following characters were measured on each plant: (1) shoot length-SLENG (mm) (2) shoot fresh weight-SFRESH (g) (3) shoot dry weightSDRY (g) (4) root length-RLENG ( $\mathrm{mm}$ ) (5) root fresh weight-RFRESH (g) (6) root dry weightRDRY (g).

For the analyses, two classes called SMALL and LARGE were defined. The class SMALL contained seeds whose initial weight was less than one half of the standard deviation from the cultivar mean seed weight while the class LARGE contained plants whose initial seed weight was greater than one half of the standard deviation above the mean. Nested analyses of variance were used to analyse the differences between SMALL and LARGE classes within each cultivar. All weight characters were log-transformed.

In all three experiments, each of the characters was analysed separately. To reduce the chances of Type I errors, only those tests with probabilities less than $0 \cdot 01$ were considered to be significant.

\section{RESULTS}

Growing barley plants from half seeds is a common practice associated with experiments to determine the genetic control of proteins and enzymes expressed in seeds or with breeding programmes for increased grain quality (e.g., Doll and Brown, 1979; Harberd and Edwards, 1982). An increase in pathogenic infection is not usually observed on half-seeds or plants grown from them and the present experiment was no exception. No mortality differences were observed between WS and HS plants grown in individual pots, either within each population or over all populations combined $\left(\chi^{2}=\right.$ $0 \cdot 003,1 \mathrm{df})$.

The analyses of experiment I, which compare WS and HS plants of ssp. spontaneum sharing maternal and paternal genotypes, appear in table 
Table 2a Differences among WS and HS plants tested for significant deviations from zero using a paired $t$-test (experiment I). See Materials and Methods for character symbols

\begin{tabular}{llrll}
\hline Character & df & $t$-value & Significance & Difference \\
\hline RADT & 259 & 7.91 & $* * *$ & faster \\
COLT & 257 & 8.42 & $* * *$ & faster \\
FLMT & 257 & 116.52 & $* * *$ & slower \\
FLFL & 257 & 244.48 & $* * *$ & shorter \\
TNO & 247 & 22.32 & $* * *$ & fewer \\
FLWT & 245 & 0.09 & ns & none \\
CLML & 234 & 0.07 & ns & none \\
FLL & 233 & 0.73 & ns & none \\
FLW & 233 & 0.02 & ns & none \\
AWNL & 234 & 0.99 & ns & none \\
HLDG & 234 & 3.06 & $* *$ & shorter \\
SPNO & 229 & 5.50 & $* * *$ & fewer \\
\hline
\end{tabular}

${ }^{\S}$ Difference describes response of HS relative to WS.

2(a). Significant differences were observed among the phenotypes of plants derived from different populations but the WS and HS means from each population showed that the direction of the differences were the same in all cases. HS plants germinated significantly faster (RADT, COLT) and had significantly shorter shoots (FLFL) and slower leaf maturation times (FLMT) than WS plants. One week after the plants had been removed from vernalization and transplanted into large pots, HS plants had significantly fewer tillers (TNO). WS and HS plants flowered (FLWT) at the same time suggesting that cutting the seed in half (or by implication, growing a small seed) did not affect the ability of spontaneum plants to perceive cues for floral induction. No significant differences were observed between WS and HS plants in culm length (CLML), flag leaf length (FLL) and width (FLW) and awn length (AWNL) although examination of the population means for these characters suggested that HS plants had a tendency towards shorter culm lengths but longer flag leaf and awn lengths. This is interesting as the grains are the main sinks for photosynthate produced by the awns and flag leaves. The length of the flowering heads (HDLG) of HS plants were significantly shorter than those of WS plants. HS plants also produced fewer spikes (SPNO) and hence fewer seeds than WS plants but the 10-seed weight (SDWT) did not differ among WS and HS plants (table 2(b)). Unfortunately, the quality of the data used to compare the final seed weights of WS and HS plants is not the same as that used for all other comparisons in experiment I. 10-seed weights were recorded for a random sample of 18 WS and $18 \mathrm{HS}$ plants from each population and
Table 2b Differences in the weight of 10 seeds produced by WS and HS plants. The nested analysis of variance was carried out on a random sample of $18 \mathrm{WS}$ and $18 \mathrm{HS}$ plants from each population. m.s. = mean square

\begin{tabular}{lrcc}
\hline Source & df & m.s. & F-ratio \\
\hline Population & 6 & $0 \cdot 8094$ & $35 \cdot 12^{* * *}$ \\
Class (within population) & 7 & 0.0231 & $1 \cdot 29 \mathrm{~ns}$ \\
Error & 238 & 0.0179 & \\
\hline
\end{tabular}

hence do not have the pair structure used for the other characters. If the similarity of final seed weight among WS and HS plants is real, it suggests that final seed number (i.e., SPNO) is positively correlated while final seed weight is uncorrelated with initial seed size. This result is consistent with that of Mazer (1987).

These data suggest why HS plants produced fewer spikes, and hence fewer seeds, than WS plants. There were fewer tillers and probably fewer primordia formed or successfully developed in HS plants at the time of flower induction which is reflected in the number of tillers which became reproductive in the later stages of the life cycle. The effects on adult fitness may thus be a carry over of the effects of initial seed size on seedling growth (see Edwards and Emara, 1970).

If all of these characters, measured over one generation, are considered together, the amount of endosperm available to an embryo can be seen to affect germination, early development and reproductive output. These fitness effects were observed among seeds which shared maternal and paternal genotype, maternal environment and growth environment and hence can be said to be due to the effects of seed size alone. But, are these results repeatable and does naturally occurring seed size variation have similar effects on these fitness variables as the experimentally induced variation?

Root and shoot characters were studied in seedlings derived from whole and half seeds in experiment II (table 3). Again, there were significant differences among each of the populations (cultivars), but an examination of the treatment means showed that the differences between WS and HS plants were similar in each case. This is also seen in table 3; except for CRNO, the interaction terms are not significant. HS plants were observed to germinate faster, and had shorter first leaves (FLFL), shoot and root lengths (SLENG, RLENG), lighter root and shoot fresh and dry weights (SFRESH. RFRESH, SDRY, RDRY) and fewer tilllers (TNO) than WS plants. All differences were significant $(P<0 \cdot 001)$. Thus, halving the 
Table 3 Mean squares, significances and direction of differences between seed classes (whole vs half) in experiment II. See Materials and Methods for character symbols. Sources: $\mathrm{POP}=$ among populations or cultivars, $\mathrm{CLASS}=$ seed class $($ whole, half $)$, POP*CLASS $=$ population by seed class interaction. m.s. $=$ mean square

\begin{tabular}{|c|c|c|c|c|c|}
\hline Character & Source & $\mathrm{df}$ & m.s. & $F$-ratio & Difference \\
\hline FLFL & $\begin{array}{l}\text { POP } \\
\text { CLASS } \\
\text { POP*CLASS } \\
\text { ERROR }\end{array}$ & $\begin{array}{r}3 \\
1 \\
3 \\
272\end{array}$ & $\begin{array}{r}332 \cdot 316 \\
126 \cdot 363 \\
3 \cdot 186 \\
1 \cdot 380\end{array}$ & $\begin{array}{c}240 \cdot 81^{* * *} \\
91 \cdot 57^{* * *} \\
2 \cdot 31\end{array}$ & shorter \\
\hline SLENG & $\begin{array}{l}\text { POP } \\
\text { CLASS } \\
\text { POP*CLASS } \\
\text { ERROR }\end{array}$ & $\begin{array}{r}3 \\
1 \\
3 \\
272\end{array}$ & $\begin{array}{l}0.934 \\
1.693 \\
0.051 \\
0.018\end{array}$ & $\begin{array}{c}51 \cdot 88^{* * *} \\
94 \cdot 06^{* * *} \\
2 \cdot 83\end{array}$ & shorter \\
\hline SFRESH & $\begin{array}{l}\text { POP } \\
\text { CLASS } \\
\text { POP*CLASS } \\
\text { ERROR }\end{array}$ & $\begin{array}{r}3 \\
1 \\
3 \\
272\end{array}$ & $\begin{array}{l}0.435 \\
1.688 \\
0.019 \\
0.006\end{array}$ & $\begin{array}{c}76 \cdot 57^{* * * *} \\
297 \cdot 43^{* * *} \\
3.40\end{array}$ & lighter \\
\hline SDRY & $\begin{array}{l}\text { POP } \\
\text { CLASS } \\
\text { POP*CLASS } \\
\text { ERROR }\end{array}$ & $\begin{array}{r}3 \\
1 \\
3 \\
272\end{array}$ & $\begin{array}{l}0.098 \\
0.543 \\
0.004 \\
0.001\end{array}$ & $\begin{array}{l}72 \cdot 95^{* * *} \\
405 \cdot 61^{* * *} \\
2.89\end{array}$ & lighter \\
\hline RLENG & $\begin{array}{l}\text { POP } \\
\text { CLASS } \\
\text { POP*CLASS } \\
\text { ERROR }\end{array}$ & $\begin{array}{r}3 \\
1 \\
3 \\
272\end{array}$ & $\begin{array}{l}0.362 \\
1.404 \\
0.030 \\
0.032\end{array}$ & $\begin{array}{c}11 \cdot 27^{* * *} \\
43 \cdot 69^{* * *} \\
0.94\end{array}$ & lighter \\
\hline RFRESH & $\begin{array}{l}\text { POP } \\
\text { CLASS } \\
\text { POP*CLASS } \\
\text { ERROR }\end{array}$ & $\begin{array}{r}3 \\
1 \\
3 \\
272\end{array}$ & $\begin{array}{l}0.499 \\
1.081 \\
0.053 \\
0.011\end{array}$ & $\begin{array}{c}46 \cdot 46^{* * *} \\
100 \cdot 64^{* * *} \\
4.96\end{array}$ & lighter \\
\hline RDRY & $\begin{array}{l}\text { POP } \\
\text { CLASS } \\
\text { POP*CLASS } \\
\text { ERROR }\end{array}$ & $\begin{array}{r}3 \\
1 \\
3 \\
271\end{array}$ & $\begin{array}{l}0 \cdot 040 \\
0 \cdot 173 \\
0 \cdot 004 \\
0 \cdot 001\end{array}$ & $\begin{array}{c}41 \cdot 59^{* * * *} \\
179 \cdot 93 * * * \\
4.38\end{array}$ & lighter \\
\hline TNO & $\begin{array}{l}\text { POP } \\
\text { CLASS } \\
\text { POP*CLASS } \\
\text { ERROR }\end{array}$ & $\begin{array}{r}3 \\
1 \\
3 \\
272\end{array}$ & $\begin{array}{r}7 \cdot 210 \\
21 \cdot 729 \\
1 \cdot 189 \\
0 \cdot 291\end{array}$ & $\begin{array}{l}24 \cdot 81^{* * *} \\
74 \cdot 79^{* * *} \\
4 \cdot 08\end{array}$ & fewer \\
\hline CRNO & $\begin{array}{l}\text { POP } \\
\text { CLASS } \\
\text { POP*CLASS } \\
\text { ERROR }\end{array}$ & $\begin{array}{r}3 \\
1 \\
3 \\
272\end{array}$ & $\begin{array}{r}15 \cdot 461 \\
200 \cdot 604 \\
27 \cdot 985 \\
1 \cdot 324\end{array}$ & $\begin{array}{r}11 \cdot 68^{* * *} \\
151 \cdot 50^{* * *} \\
21 \cdot 13^{* * *}\end{array}$ & fewer \\
\hline
\end{tabular}

${ }^{\&}$ Difference describes response of HS relative to WS.

seed had similar effects on seedling characters in both experiments I and II.

The purpose of experiment III was, by comparing it to experiment II, to see if large and small seeds produced effects on seedling characters similar to those of whole and half seeds. The results are presented in table 4. Plants from SMALL seeds were observed to germinate faster than plants from LARGE seeds and in addition, had significantly shorter shoots (SLENG) and lighter shoot and root fresh and dry weights (SFRESH, SDRY, RFRESH, RDRY). No significant differen- ces in root lengths were observed between plants coming from LARGE and SMALL seeds.

Germination times, root and shoot lengths and fresh and dry weights were studied in both experiments II and III. In all characters, except root length, the direction and significances of the differences between WS and HS plants (experiment II) were the same as those between SMALL and LARGE seeds (experiment III). Although both small and half seeds germinated relatively faster than large and whole seeds, half seeds germinated relatively faster than small seeds. This is 
Table 4 Mean squares, $F$-ratios and direction of differences between seed classes (LARGE vs SMALL) within cultivars in experiment III. See Materials and Methods for character symbols. Sources: CVS = cultivar, CLASS $(\mathrm{CVC})=$ seed class within cultivar. $\mathrm{m} . \mathrm{s} .=$ mean square

\begin{tabular}{|c|c|c|c|c|c|}
\hline Character & Source & df & m.s. & $F$-ratio & Difference \\
\hline SDWT & $\begin{array}{l}\text { CVS } \\
\text { CLASS(CVS) } \\
\text { ERROR }\end{array}$ & $\begin{array}{r}1 \\
2 \\
31\end{array}$ & $\begin{array}{r}65 \cdot 136 \\
1791 \cdot 325 \\
11 \cdot 699\end{array}$ & $\begin{array}{c}5 \cdot 75 \\
158 \cdot 22^{* * *}\end{array}$ & lighter \\
\hline SLENG & $\begin{array}{l}\text { CVS } \\
\text { CLASS(CVS) } \\
\text { ERROR }\end{array}$ & $\begin{array}{r}1 \\
2 \\
30\end{array}$ & $\begin{array}{r}1 \cdot 413 \\
20 \cdot 100 \\
4 \cdot 179\end{array}$ & $\begin{array}{l}0 \cdot 34 \\
4 \cdot 81^{*}\end{array}$ & shorter \\
\hline SFRESH & $\begin{array}{l}\text { CVS } \\
\text { CLASS(CVS) } \\
\text { ERROR }\end{array}$ & $\begin{array}{r}1 \\
2 \\
30\end{array}$ & $\begin{array}{l}4 \cdot 243 \\
0 \cdot 392 \\
0 \cdot 031\end{array}$ & $\begin{array}{r}139 \cdot 18^{* * *} \\
12 \cdot 85^{* * *}\end{array}$ & lighter \\
\hline SDRY & $\begin{array}{l}\text { CVS } \\
\text { CLASS(CVS) } \\
\text { ERROR }\end{array}$ & $\begin{array}{r}1 \\
2 \\
30\end{array}$ & $\begin{array}{l}0 \cdot 0360 \\
0 \cdot 0041 \\
0 \cdot 0004\end{array}$ & $\begin{array}{l}98 \cdot 39^{* * *} \\
11 \cdot 32^{* * *}\end{array}$ & lighter \\
\hline RLENG & $\begin{array}{l}\text { CVS } \\
\text { CLASS(CVS) } \\
\text { ERROR }\end{array}$ & $\begin{array}{r}1 \\
2 \\
30\end{array}$ & $\begin{array}{r}3 \cdot 479 \\
0 \cdot 276 \\
11 \cdot 722\end{array}$ & $\begin{array}{l}0 \cdot 30 \\
0 \cdot 02\end{array}$ & none \\
\hline RFRESH & $\begin{array}{l}\text { CVS } \\
\text { CLASS(CVS) } \\
\text { ERROR }\end{array}$ & $\begin{array}{r}1 \\
2 \\
30\end{array}$ & $\begin{array}{l}0 \cdot 008 \\
0 \cdot 042 \\
0 \cdot 006\end{array}$ & $\begin{array}{l}1 \cdot 32 \\
7 \cdot 14^{* *}\end{array}$ & lighter \\
\hline RDRY & $\begin{array}{l}\text { CVS } \\
\text { CLASS(CVS) } \\
\text { ERROR }\end{array}$ & $\begin{array}{r}1 \\
2 \\
30\end{array}$ & $\begin{array}{l}0 \cdot 0006 \\
0 \cdot 00024 \\
0 \cdot 00003\end{array}$ & $\begin{array}{l}2 \cdot 02 \\
8 \cdot 42^{* * * *}\end{array}$ & lighter \\
\hline
\end{tabular}

probably due to the half seed coat allowing water to enter and activate the germination process more quickly. Nonetheless, the similarities between the two experiments suggest that predictions from the behaviour of whole and half seeds can be made about the behaviour of large and small seeds, at least at a qualitative level.

These experiments also suggest that the amount of endosperm available to an embryo, independent of genetic effects, affects the subsequent development of the plant. These results have one further implication for the design and interpretation of experiments in which phenotypic variation in plant quantitative characters is to be partitioned. Because the size of the seed influences characters measured later in the life cycle, it may introduce undesired sources of variation. Such experiments should be carried out using seeds of the same size or the variances calculated conditional on initial seed size.

\section{DISCUSSION}

Using pairs of seeds from single flowering heads of a self-fertilizing plant ( $H$. v. ssp. spontaneum) as the unit of comparison means that the seed pairs share maternal and paternal genotypes and maternal environment. Growing these pairs in the same experimental environment then allows the effects of different amounts of endosperm to be studied without confounding genetic and seed size effects. When this was done, seed size was found to affect the time of germination, vegetative growth rates and the numbers of seeds produced suggesting that the size of a seed affects the viability and/or fecundity of the plant it produces, in the absence of genetic and environmental differences. As in other studies, the large seeds appeared to produce plants with the highest fitness in terms of the "number of seeds produced per plant". However, if the "mean weight (size) of seeds produced" is considered instead, no significant differences were observed among plants which grew from seeds containing different amounts of maternal resource.

Similar results can be found in the literature. Johannsen (1903) observed that the mean seed size of 19 pure (inbreeding) lines of Phaseolus vulgaris did not change over successive generations regardless of whether he selected small, medium or large seeds within a single line or pod. Johannsen was also interested in the variability of pure lines, and 
consequently measured the variation in the 19 lines over several generations. "There is no indication as to diminution of variability in the course of generations by cultivation of pure lines ... (in fact) ... there is no alteration, the standard deviation skewness, and so on, are the same for the same pure line, year after year" (Johannsen, 1906). Johannsen also identified the major source of the within-plant/line variation as due to the positions of the seeds within the pods, but then concluded, in spite of the nonrandom and apparently "true breeding" nature of the variation, that since this variation was somatic, it was extrinsic to the germline variability and thus environmental. By definition, environmental variance does not behave as Johannsen observed, hence, I feel it is unlikely that variation due to position effects is purely environmental.

In a recent experiment, Jarosz et al., (1989) studied the effects of mildew infection (Erysiphe graminis f. sp. tritici) on seed size in wheat, Triticum aestivum (Poaceae). Four lines of seed, generated on the basis of high and low seed weight and whether the seed came from disease-free or infected parents, were compared under otherwise similar environmental conditions. The mildew infection significantly reduced the mean size of seeds produced by the infected plants compared to disease-free controls by increasing the number of seeds falling into smaller size classes without changing the range of size classes produced. When the seeds harvested from the infected parents were then planted, they grew into plants producing fewer ears, and hence seeds, than the plants grown from seed harvested from the controls. However, the mean weights of the seeds produced by the offspring of infected and non-infected parents did not differ. Infection-created small seeds appear to have behaved as any other small seed, namely, capable of growing into plants producing large and small seeds. While these results clearly illustrate that the environment of the mother plant (here, mildew infection) influences seed size (by reducing the mean but not the range of sizes produced), they also show that the characteristic mean size is regenerated.

Johannsen's, Jarosz et al's, and my results, all obtained from inbreeding plants which typically produce seeds whose sizes vary as a result of their position on the maternal plant, indicate that a seed, regardless of its initial size, is capable of regenerating the same mean size. Johannsen's data also show that the same variation is regenerated. This suggests that it is not a particular seed size which is inherited but a distribution of sizes, and that the mean, alone, is insufficient to describe the seed size of a genotype. Position effects are the agents creating these size distributions and they ensure that seed size variation is produced every generation. This is why the expected reduction in seed size variance is not observed in spite of strong selection on seed size in the growth environment, at least in species belonging to the Asteraceae, Chenopodiaceae, Poaceae, Leguminaceae or Brassicaceae.

But, are these position effects due to "constraints" with little variation among individuals, or is there any evidence to suggest that there is genetic variation for position effects upon which selection could act? Support for the latter requires that inherited variation is found among genotypes (within and/or among populations) in the structural organization of the position effects on the plants and/or in the distributions of seed sizes on a plant. In a recent experiment designed to see whether Johannsen's observations could be repeated in wild barley, I included plants from two populations recently obtained from China (Giles, in preparation). In these populations, the large to small size gradient did not run from the middle towards the base and top of the head as it does in the plants used here, but instead, ran from the base to the top of the head. McGinley (in press) reports that "seeds from the centre of the receptacle tend to be smaller than seeds from the edge of the receptacle in the wavyleaf thistle (Circium undulatum) although this pattern was reversed in some heads", and further, that "similar patterns have been observed in other members of the Asteraceae (Tragopogon dubious and Taraxacum officinale, McGinley, unpublished)". Other examples of altered (and true breeding) position effects are reported for horticultural varieties of various members of the Asteraceae by Harper (1977, p. 72). A number of crop species belong to one of the five families whose seeds are known to vary from position effects. This variation has often been considered undesirable from a marketing point of view. In peas, beans, and sorghum (e.g., Ambrose and Hedley, 1984; Fehr and Weber, 1968; Hedley and Ambrose, 1981; Voight et al., 1966), it has been possible to find and consciously select plants producing more uniform seed sizes. Further, if the heritabilities of mean seed size, estimated from plants artifically selected for seed size uniformity, are compared with those of wild plants whose seeds vary in size from position effects, large differences are apparent; the heritabilities in the selected plants Glycine max (Fehr and Weber, 1968) and Sorghum vulgare (Voight et al., 1966) have been 
estimated to be 0.93 and 0.6 , respectively, whereas $h^{2}=0.09$ in wild Lupinus texensis (Schaal, 1980). That the within-plant variation can be selectively removed and that once removed, more of the total variance in seed size appears to be explained by differences among genotypes, also suggests that there may be genetic variation for within-plant variation in seed size. Thus selection could act to increase the frequencies of genotypes with particular distributions of seed sizes or position arrangements. How much genetic variation exists for these size distributions among different genotypes, and how environmental variation influences the size distributions, has never been studied directly.

While more work must be done to determine the nature of seed size variation before much can be said about seed size evolution, several models attempting to explain the maintenance of size variation as an adaptation to spatial and temporal environmental variability exist. Two basic classes of mathematical models have been used. McGinley et al. (1987) and Smith and Fretwell (1974) used optimisation models. Based on the observation that larger seeds often appear to be fitter, they have assumed that beyond a threshold level of investment, the arithmetic mean fitness is a monotonically increasing function of size in all environments (no "size" by environment interaction). They then show that when the temporal or spatial environment varies randomly, parental fitness is maximised by investing equally in all offspring and that larger offspring do better than smaller offspring in all environments; i.e., environmental heterogeneity cannot selectively maintain seed size variability. These are the same models (see Introduction) which predicted that the variance in seed size should decrease in natural populations due to strong selection towards seeds of a similar and larger size. The "developmental constraints" argument (McGinley et al., 1987 and Introduction) has consequently been used to explain the maintenance of the variation; developmental constraints prevent parents from attaining maximum fitness and contain no variation available to selection. Alternatively, various forms of "bet-hedging" models do predict that the production of variably sized offspring will be selectively advantageous when environments vary at random (e.g., Cohen, 1966, 1967; Harper, 1977; Kaplan and Cooper, 1984; Philippi and Seger, 1989; Real, 1980; Silvertown, 1984, 1989; Westoby, 1981; some of these models are verbal and/or use dormancy and germination "polymorphisms" which are either correlated with seed size or produced by mechanisms which may also account for size variation). In these models, the genotypes with the highest geometric mean fitness over generations are those with the smallest variances in their mean fitnesses among generations (geometric mean fitness is appropriate when the fitness of a genotype varies over generations and environments (Philippi and Seger, 1989)). Paradoxically, genotypes achieve a smaller variance in mean fitness between generations by increasing the variance in fitness among their offspring in each generation ("diversified" bethedging; Philippi and Seger, 1989).

As discussed, position effects are the agents creating seed size distributions and ensure that seed size variation is produced every generation. Strong circumstantial evidence (now being verified) suggests that position effects are inherited, that variation in their organization and expression exists, and that a seed of any size can regenerate the size distribution although different numbers of seeds are produced by plants grown from seeds of different sizes. In light of the two types of models described above, these biological observations are more consistent with the assumptions used in the bet-hedging models than those of the optimization models. Position effects make plants diversified bet-hedgers, not only at the level of a single genotype, but also at the level of an individual plant. Alternatively, Kaplan and Cooper (1984) use the term "adaptive coin-flipping" which they define as adaptive random variation generated by developmental mechanisms. Where developmental mechanisms are Kaplan and Cooper's "coin", position effects are the "coin" available to certain" groups of plants for the generation of withingenotype variation. Contrary to the random variation envisaged by Kaplan and Cooper, variation generated by position effects may not be random, but continuous within upper and lower limits. The inherited and regenerating position effects provide a plant with a pre-programmed set of coin-flip results.

That seeds of different sizes germinate, grow and reproduce at different rates in the same environment suggests that seed size variation could be advantageous in randomly varying environments. Since phenotypic variance in seed size within a genotype can reduce the variance in fitness of a genotype over time and space, the probability of stochastic loss of genotypes from populations will consequently be reduced. If selection acts on the seed size distributions produced by different genotypes, the important question for the evolution of seed size may be which distributions are favoured by selection. Further theoretical con- 
siderations of the evolutionary significance of seed size variation will be the subject of future papers (Barrett and Giles, in preparation).

Acknowledgements I am extremely grateful to Inga Mattiasson who organized experiments II and III and to Lotta Claesson without whom experiment I would have been impossible. Eviatar Nevo collected the kindly donated the material. I am also indebted to the unknown "hordein analyst" who inadvertently created the whole seed/half seed pairs thereby suggesting this experiment. The discussions and criticisms of John Barrett, Jeremy Burdon, Honor Prentice and Maureen Stanton were invaluable for the revision of this manuscript. This research was supported by a grant from the Swedish Council for Forestry and Agricultural Research.

\section{REFERENCES}

AMBrose, M. J. AND HEDLEY, C. L. 1984. A population study to aid the selection of improved dried pea (Pisum sativum) crop plants. Annl. Bot., 53, 655-662.

ALEXANDER, H. M. AND WULFF, R. D. 1985. Experimental ecological genetics in Plantago X. The effects of maternal temperature on seed and seedling characters in $P$. lanceolata. J. Ecol., 73, 271-282.

ANTONOVICS, J. AND SCHMITT, J. Paternal and maternal effects on propagule size in Anthoxanthum odoratum. Oecologia (Berlin), 69, 277-282.

BAKER, H. G. Seed weight in relation to environmental conditions in California. Ecology, 53, 997-1010.

BLACK, J. N. 1957. Seed size as a factor in the growth of subterranean clover (Trifolium subterraneum L.) under spaced and sward conditions. Aust. J. Agric. Res., 8, 335351.

BRADFORD, D. F. AND SMITH, C. C. 1977. Seed predation and seed number in Scheelea palm fruits. Ecology, 58, 667-673.

BROWN, A. H. D., ZOHARY, D. AND NEVO, E. 1978a. Outcrossing rates and heterozygosity in natural populations of Hordeum spontaneum Koch in Israel. Evolution, 33, 815833.

BROWN, A. H. D., NEVO, E., ZOHARY, D. AND DAGAN, O. $1978 \mathrm{~b}$. Genetic variation in natural populations of wild barley (Hordeum spontaneum). Genetica, 49, 97-108.

CAVERS, P. B. AND STEEL, M. G. 1984. Patterns of change in seed weight over time on individual plants. Amer. Natur., 124, 324-335.

CIDECIYAN, M. A. AND MALLOCH, A. J. C. 1982. Effects of seed size on germination, growth and competitive ability of Rumex crispus and Rumex obtusifolius. J. Ecol., 70, $227-$ 232.

COHEN, D. 1966. Optimizing reproduction in a randomly varying environment. $J$. Theor. Biol, 12, 119-129.

COHEN, D. 1967. Optimizing reproduction in a randomly varying environment when a correlation may exist between the conditions at the time a choice has to be made and the subsequent outcomes. J. Theor. Biol., 16, 1-14.

DOLL, H. AND BROWN, A. H. D. 1979. Hordein variation in wild (Hordeum spontaneum) and cultivated (H. vulgare) barley. Can. J. Genet. Cytol., 21, 391-404.

EDWARDS, K. J. R. AND EMARA, Y. A. 1970, Variation in plant development within a population of Lolium multiflorum. Heredity, 25, 179-194.
FEHR, W. R. AND WEBER, C. R. 1968. Mass selection by seed size and specific gravity in soybean populations. Crop Sci., $8,551-554$.

GILES, B. E. AND BENGTSSON, B. O. 1988. Variation in anther size in wild barley (Hordeum vulgare spp. spontaneum). Hereditas, 108, 199-205.

GIles, B. E. AND LefKovitCh, L. P. 1985. Agronomic differences in Hordeum spontaneum from Iran and Morocco. Z. Pflanzenzüchtg., 94, 25-40.

HARBERD, N. P. AND EDWARDS, K. J. R. 1982. A mutational analysis of the alcohol dehydrogenase system in barley. Heredity, 48, 187-195.

HARPer, J. L. 1977. Population Biology of Plants. Academic Press, New York, U.S.A.

HARPER, J. L. LOWELL, P. H. AND MOORE, K. G. 1970. The shapes and sizes of seeds. Ann. Rev. Ecol. Syst., 1, 327356.

HEDLEY, C. L. AND AMBROSE, M. J. 1981. Designing “leafless" plants for improving yields of the dried pea crop. Adv. Agron., 34, 225-277.

JAROSZ, A. M., BURDON, J. J. AND MÜLLER, W. J. 1989. Long-term effects of disease epidemics. J. Appl. Ecol., In press.

JANZEN, D. H. 1977. Variation in seed size within a crop of a Costa Rican Mucuna andreana (Leguminosae). Amer. J. Bot., 64, 347-349.

JOHANNSEN, W. 1903. Om arvelighed i samfund og i rene linier. Oversigt over det Kongelige Danske Videnskabernes Selskabs forhandlinger, No. 3, 247-270.

JOHANNSEN, w. 1906. Does hybridization increase fluctuating variability? In Wilks, W. (ed.) Report of the Third International Conference on Genetics, Royal Horticultural Society, Spottiswoode \& Co. Ltd., London.

KAPLAN, R. H. AND COOPER, w. S. 1984. The evolution of developmental plasticity in reproductive characteristics: an application of the "adaptive coin-flipping" principle. Amer. Natur., 123, 393-410.

MAZER, S. J. The quantitative genetics of life history and fitness components in Raphanus raphanistrum L. (Brassicaceae): Ecological and evolutionary consequences of seed-weight variation. Amer. Natur., 130, 891-914.

MAZER, S. J., SNOW, A. A. AND STANTON, M. L. 1986. Fertilization dynamics and parental effects upon fruit development in Raphanus raphanistrum: consequences for seed size variation. Amer. J. Bot., 73, 500-511.

McGINLEY, M. A. Individual seed mass variation in Cirsium undulatum (Nutt.) Spteng. (Asteraceae): The role of selectively favoured variation and physiological constraints. Amer. J. Bot., (In press).

McGinley, M. A., TEMME, D. H. AND GEBER, M. A. 1987. Parental investment in offspring in variable environments: Theoretical and empirical considerations. Amer. Natur., 130, 370-398.

MORSE, D. H. AND SCHMITT, J. 1985. Propagule size, dispersal ability, and seedling performance in Asclepias syriaca. Oecologia (Berlin), 76, 372-379.

NAYLOR, A. 1964. Natural selection through maternal influence. Heredity, 19, 509-511.

NICKELL, C. D. AND GRAFIUS, J. E. 1969. Analysis of a vegetative response to selection for high yield in winter barley. Crop Sci, 9, 447-451.

PHILIPPI, T. and SEGER, J. 1989. Hedging one's evolutionary bets, revisited. TREE, 4, 41-44

OLSSON, G. 1960. Some relations between number of seeds per pod, seed size and oil content, and the effect of selection for these characters in Brassica and Sinapis. Hereditas, 46, 29-70. 
PITElKA, L. F., THAYER, M. E. AND HANSEN, S. B. 1983. Variation in achene weight in Aster acuminatus. Can. J. Bot., 61, 1415-1420.

REAL, L. 1980. Fitness, uncertainty, and the role of diversification in evolution and behaviour. Amer. Natur., 115, 623-638.

ROACH, D. A. AND WULFF, R. D. 1987. Maternal effects in plant. Ann. Rev. Ecol. Syst., 18, 209-235.

SCHAAL, B. A. 1980. Reproductive capacity and seed size in Lupinus texensis. Amer. J. Bot., 67, 703-709.

SCHAAL, B. A. 1984. Life-history variation, natural selection and maternal effects in plant populations. In Dirzo, R. and Sarukhan, J. (eds). In Perspectives in Plant Population Ecology. Sinauer, Mass. U.S.A.

SIlvertoWN, J. W. 1984. Phenotypic variety in seed germination behaviour: the ontogeny and evolution of somatic polymorphism in seeds. Amer. Natur., 124, 1-16.

SILVERTOWN, J. W. 1989. The paradox of seed size and adaptation. TREE, 4, 24-26.

SMITH, C. C. AND FRETWELL, S. D. 1974. The optimal balance between size and number of offspring. Amer. Natur., 108, 499-506.

StANTON, M. L. 1984a. Seed variation in wild radish: Effect of seed size on components of seedling and adult fitness. Ecology, 65, 1105-1112.

STANTON, M. L. 1984b. Developmental and genetic sources of seed weight variation in Raphanus raphanistrum $\mathrm{L}$. (Brassicaceae). Amer. J. Bot., 71, 1090-1098.
STANTON, M. L. 1985. Seed size and emergence time within a stand of wild radish (Raphanus raphanistrum L.): the establishment of a fitness hierarchy. Oecologia (Berlin), 67, 524-531.

VOIGHT, R. L., GARDINER, C. O. AND WEBSTER, O. J. 1966 Inheritance of seed size in Sorghum, Sorghum vulgare Pers. Crop Sci., 6, 582-586.

WALLER, D. M. 1982. Factors influencing seed weight in Impatiens capensis (Balsaminaceae). Amer. J. Bot., 69, 1470-1475.

WERNER, F. A. AND PLATT, W. J. 1976. Ecological relationships of co-occurring goldenrods (Solidago: Compositae). Amer. Natur., 110, 959-971.

WESTOBY, M. 1981. How diversified seed germination behaviour is selected. Amer. Natur., 118, 882-885.

WOLF, L. L., HAINSWORTH, F. R., MERCIER, T. AND BEN JAMIN, R. 1986. Seed size variation and pollinator uncertainty in Ipomopsis aggregata (Polemoniaceae). J. Ecol., 74, 361-371.

WUlfF, R. D. 1986a. Seed size variation in Desmodium paniculatum. I. Factors affecting seed size. J. Ecol., 74, 87-98.

WUlfF, R. D. 1986 b. Seed size variation in Desmodium paniculatum. II. Effects on seedling growth and physiological performance. J. Ecol., 74, 99-114.

WULFF, R. D. 1986 c. Seed size variation in Desmodium paniculatum. III. Effects on reproductive yield and competitive ability. J. Ecol, 74, 115-121. 